\title{
An adrenal rest tumour in the perirenal region in a patient with congenital adrenal hyperplasia due to congenital $3 \beta$-hydroxysteroid dehydrogenase deficiency
}

\author{
Hedi L Claahsen-van der Grinten ${ }^{1}$, Kristof Duthoi ${ }^{2}$, Barto J Otten ${ }^{1}$, Frank C H d'Ancona ${ }^{3}$, \\ Christina A Hulsbergen-vd $\mathrm{Kaa}^{2}$ and Ad R M M Hermus ${ }^{4}$ \\ Departments of ${ }^{1}$ Paediatric Endocrinology (833), ${ }^{2}$ Pathology, ${ }^{3}$ Urology and ${ }^{4}$ Endocrinology, Radboud University Nijmegen Medical Centre, \\ PO Box 9101, 6500 HB Nijmegen, The Netherlands \\ (Correspondence should be addressed to H L Claahsen-van der Grinten; Email: h.claahsen@cukz.umcn.nl)
}

\begin{abstract}
Background: In contrast to the high incidence of testicular adrenal rest tumours (TART) in adult male patients with congenital adrenal hyperplasia (CAH), ovarian adrenal rest tumours in female $\mathrm{CAH}$ patients are very rare and other locations of adrenal rest tumours have never been reported. Here, we report on an adult patient with $\mathrm{CAH}$ due to $3 \beta$-hydroxysteroid dehydrogenase (HSD) deficiency with bilateral TART and additionally a large perirenal adrenal rest tumour.

Case report: The patient was known with CAH due to $3 \beta$-HSD deficiency and treated with hydrocortisone and fludrocortisone since the neonatal period. In puberty, there was lack of compliance with consequently high POMC concentrations. At the age of 16 years, bilateral TART were detected by scrotal ultrasound. Intensifying glucocorticoid medication did not result in decrease in POMC concentrations and shrinkage of size of the tumours. At the age of 23 years, abdominal ultrasound was performed because of abdominal complaints, showing a round inhomogeneous structure with a diameter of $4 \mathrm{~cm}$ near the left renal hilus. A computer tomography scan showed a multinodular lesion in the retroperitoneal region beside the left kidney. Histological investigation after removal of the tumour showed sheets of large polygonal cells with abundant eosinophilic cytoplasm, separated by dense fibrous tissue strands. The histological and immunohistochemical profile resulted in a diagnosis of an adrenal rest tumour.

Conclusion: In adult CAH patients, ectopic adrenal rest tumours can be present outside the testicular region. Further investigations are necessary to determine whether regularly screening for these tumours is useful.
\end{abstract}

European Journal of Endocrinology 159 489-491

\section{Introduction}

Ectopic adrenocortical tissue is a common incidental finding during abdominal or inguinal operations in infants without clinical implications. Typical locations are within the testes, the celiac plexus and along the spermatic cord (1-6). Other rare locations are the liver and the spinal canal $(7,8)$.

In adult male patients with congenital adrenal hyperplasia $(\mathrm{CAH})$, the presence of ectopic adrenocortical tissue in the testes can lead to the development of testicular adrenal rest tumours (TART). The aberrant adrenocortical cells within the testes are stimulated by pro-opiomelanocortin (POMC) in periods of suboptimal hormonal control inducing hypertrophy and hyperplasia (9). This hypothesis is supported by the presence of POMC receptors on tumour tissue and by the fact that TART also occur in other conditions with elevated plasma POMC concentrations such as Nelson's syndrome and Addison's disease $(10,11)$. Furthermore, the presence of angiotensin II (AII) receptors on TART is additional evidence that the tumours arise from adrenal-like cells (11).

In contrast to the high incidence of TART in adult male $\mathrm{CAH}$ patients (up to 94\%) $(12,13)$, ovarian adrenal rest tumours in female $\mathrm{CAH}$ patients are very rare (14) and other locations of adrenal rest tumours in adult $\mathrm{CAH}$ patients have never been reported. Here, we report on an adult patient with $\mathrm{CAH}$ due to $3 \beta$-hydroxysteroid dehydrogenase (HSD) deficiency with bilateral TART and additionally a large perirenal adrenal rest tumour.

\section{Case report}

The patient was known with CAH due to HSD deficiency and was treated with hydrocortisone and fludrocortisone since the neonatal period. The diagnosis was confirmed by 
mutation analysis (homozygous 694C $>\mathrm{G}$ mutation within the HSD $3 B 2$ gene). He was treated by a paediatric endocrinologist (BO) until adult age and thereafter he was treated by an adult endocrinologist $(\mathrm{A} \mathrm{H})$ in the same centre. His adult height was $159.5 \mathrm{~cm}(-3.5 \mathrm{SDS})$. Since the pubertal period there was lack of compliance with consequently high plasma POMC concentrations. At the age of 16 years, bilateral TART were detected by scrotal ultrasound. Intensifying glucocorticoid medication did not result in a decrease in plasma POMC concentrations and shrinkage of the size of the tumours. At the age of 23 years, abdominal ultrasound was performed because of complaints of nausea and vomiting since several years, showing a round inhomogeneous structure with a diameter of $4 \mathrm{~cm}$ retroperitoneally near the left renal hilus. A computer tomography scan of the whole abdomen showed a lesion of $5.2 \times 4.5 \times 3.4 \mathrm{~cm}$ with a multinodular aspect located in the retroperitoneal region beside the left kidney without pathological lymph nodes (Fig. 1). The tumour was totally removed laparoscopically without complications and was investigated histologically. As expected hormonal control did not improve after surgery. The patients complaints did not resolve. Further investigations showed a sliding hiatus hernia diaphragmatica explaining the symptoms in this patient.

\section{Histopathology}

Macroscopically, the tumour measured $6.5 \times 4.5 \times 3 \mathrm{~cm}$ and was encapsulated with a thin, smooth, fibrous capsule. The tumour had a firm consistency with a variable brown to yellow colour on cross-section. There were no haemorrhages, necrosis or cystic variations.

On microscopical examination, the tumour consisted of large polygonal cells with abundant eosinophilic cytoplasm, which showed focal peripheral basophilic granules and sometimes fine, clear vacuolation. Occasionally, there was some lipofuchsin pigment (Fig. 2).

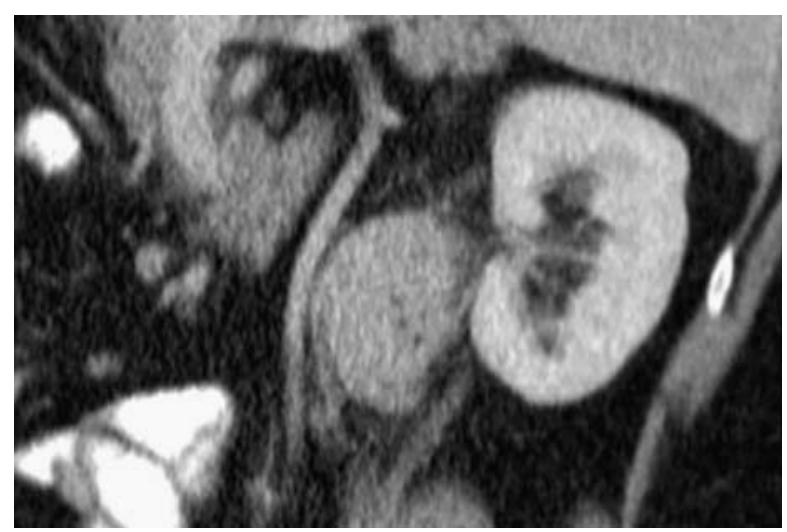

Figure 1 Abdominal computer tomography scan showing a multinodular, retroperitoneal lesion of $3.4 \times 4.5 \mathrm{~cm}$ without pathological lymph nodes near the left renal hilus.
The nuclei were round and of varying size with a large eosinophilic nucleolus. Occasional nuclei were hyperchromatic or showed polylobulation or a cytoplasmic inclusion vacuole. No mitotic figures were seen.

The cells were growing in a sheet-like pattern forming small nests and cords, incompletely divided by fibrotic septa. Within these septa, lymphoplasmacellular infiltrates with rare eosinophils were present. Mature adipocytic cells were admixed among the tumour cells.

Immunohistochemical stains showed the tumour cells to be positive for cytokeratins $8 / 18$ and inhibin. They were negative for pancytokeratine AE1/AE3, epithelial membrane antigen, histiocytic marker CD68, renal cell carcinoma marker CD10 and placental-like alkaline phosphatase.

The histological and immunohistochemical profile resulted in a diagnosis of an adrenal rest tumour.

\section{Discussion}

This is the first report of an adult CAH patient with a large adrenal rest tumour outside the testes. The tumour was located in the perirenal region. Interestingly, despite the reported high incidence of adrenal rests at various locations in healthy infants only adrenal rests within the testes seem to be of clinical importance in $\mathrm{CAH}$ patients. It is known that during the embryological period, the adrenal glands develop in the vicinity of the gonads. Adrenocortical cells may then nestle within the testes or descend together with the testes within the retroperitoneal region. Therefore, the most common location of adrenal rests is within the testes or along the spermatic cord. It is hypothesized that in the presence of high plasma POMC concentrations, these cells can proliferate leading to the development of adrenal rest tumours. Interestingly, in a recent study, Val et al. describe a novel population of adrenal-like cells in the mouse testis originating from adreno-gonadal primordial steroidogenic cells (15). They speculate that TART in $\mathrm{CAH}$ patients may have their origin from these tissues. However, these findings have to be translated with caution as mouse foetal testes express POMC receptors in contrast to the developing human testes.

In $\mathrm{CAH}$ patients, the presence of TART is well known and most clinicians actually screen their patients for these tumours, who are often not palpable (16). So far extra-testicular locations of adrenal rest tumours have not been reported in adult male $\mathrm{CAH}$ patients. This may be because of the low incidence of these tumours or because these tumours generally do not lead to serious complaints and patients are not regularly screened for extra-testicular locations. However, ectopic adrenal rest tissue may have clinical significance. First, ectopic adrenal cells may be hormonally active, contributing to the pathological steroid production in CAH patients. Especially in adrenalectomized patients, this may cause 

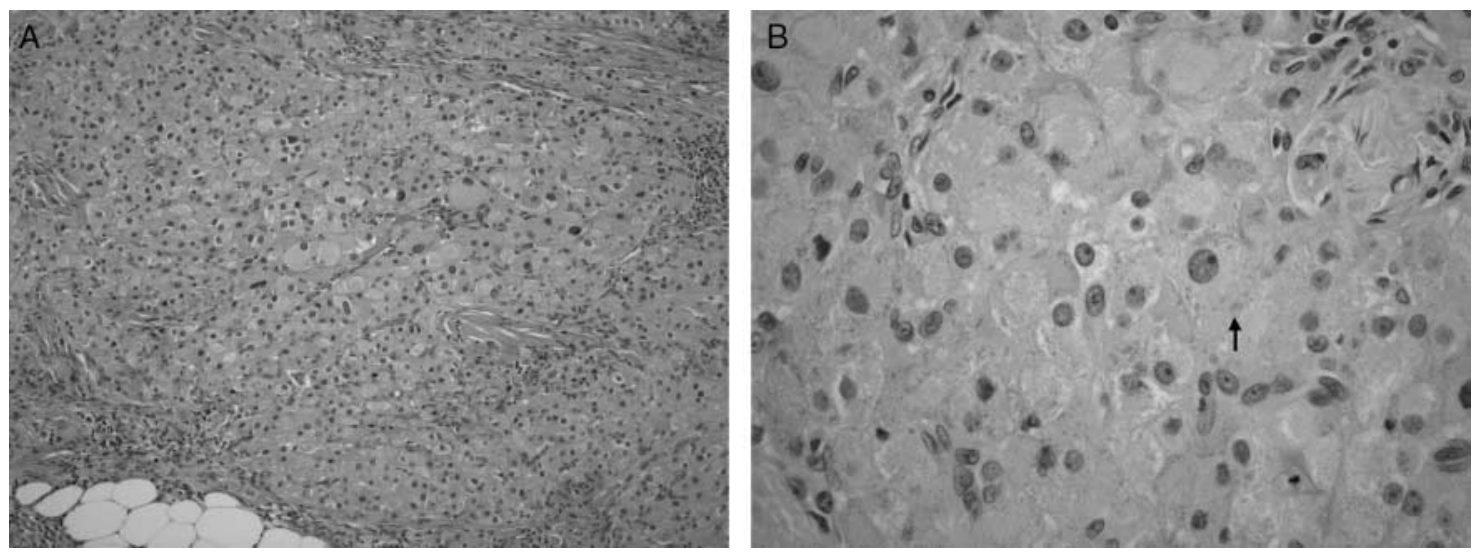

Figure $2(A)$ Microscopy of the tumour at low magnification $(\times 100)$, showing sheets of large polygonal cells with thin fibrovascular septa and few adipocytes (left lower corner). (B) The tumour cells have ample eosinophilic cytoplasm with faint basophilic granules (arrow head). Nuclei are round with prominent nucleoli $(\times 400)$.

persistently elevated adrenal steroid levels after surgery. Second, malignant degeneration of adrenal rests has been described (17). Future investigations are necessary to determine whether regularly screening for these tumours is useful.

\section{References}

1 Altin MA, Guendogdu ZH \& Aksoy F. Adrenal rests in the inguinal region in children. Pediatric Surgery International 19927 446-448.

2 Souverijns G, Peene P, Keuleers H \& Vanbockrijck M. Ectopic localization of adrenal cortex. European Radiology 200010 1165-1168.

3 Savas C, Candir O, Bezir M \& Cakmak M. Ectopic adrenocortical nodules along the spermatic cord of children. International Urology and Nephrology $200132681-685$.

4 Ozel SK, Kazez A \& Akpolat N. Presence of ectopic adrenocortical tissues in inguinoscrotal region suggests an association with undescended testis. Pediatric Surgery International 200723 171-175.

5 Mednez R, Tellado MG, Somoza I, Liras J, Sanchez-Abuin A, Pais E \& Vela D. Ectopic adrenal tissue in the spermatic cord in pediatric patients: surgical implications. International Brazilian Journal of Urology 200632 202-207.

6 Ventura L, Leocata P, Hind A, Greco I \& Ventura T. Ectopic adrenal tissue in the spermatic cord. Case report and review of the literature. Archivio Italiano di Urologia, Andrologia 1998 70 15-18.

7 Kepes JJ, O’Boynick P, Jones S, Baum D, McMillan J \& Adams ME. Adrenocortical adenoma in the spinal canal of an 8-year old girl. American Journal of Surgical Pathology 199014 481-484.

8 Tajima T, Funakoshi A, Ikeda Y, Hachitanda Y, Yamaguchi M, Yokota M, Yabuuchi H, Satoh T \& Koga M. Nonfunctioning adrenal rest tumour of the liver: radiologic appearance. Journal of Computer Assisted Tomography 200125 98-101.

9 Cabrera MS, Vogiatzi MG \& New MI. Long term outcome in adult males with classic congenital adrenal hyperplasia. Journal of Clinical Endocrinology and Metabolism 200186 3070-3078.
10 Stikkelbroeck NMML, Otten BJ, Pasic A, Jager GJ, Sweep CGJ, Noordam K \& Hermus ARMM. High prevalence of testicular adrenal rest tumours, impaired spermatogenesis, and Leydig cell failure in adolescent and adult males with congenital adrenal hyperplasia. Journal of Clinical Endocrinology and Metabolism 2001 86 5721-5728.

11 Claahsen-van der Grinten HL, Otten BJ, Sweep FC, Span PN, Ross HA, Meuleman EJ \& Hermus AR. Testicular tumours in patients with congenital adrenal hyperplasia due to 21-hydroxylase deficiency show functional features of adrenocortical tissue. Journal of Clinical Endocrinology and Metabolism $2007 \mathbf{9 2}$ 3674-3680.

12 Hamwi GJ, Gwinup G, Mostow JH \& Besch PK. Activation of testicular adrenal rest tissue by prolonged excessive ACTH production. Journal of Clinical Endocrinology and Metabolism 1963 23 861-869.

13 Johnson RE \& Scheithauer B. Massive hyperplasia of the testicular adrenal rests in a patient with Nelson's syndrome. American Journal of Clinical Pathology 19827 501-507.

14 Claahsen-van der Grinten HL, Hulsbergen-van de Kaa CA \& Otten BJ. Overian adrenal rest tissue in congenital adrenal hyperplasia - a patient report. Journal of Pediatric Endocrinology and Metabolism $200619177-182$.

15 Val P, Jeays-Ward K \& Swain A. Identification of a novel population of adrenal-like cells in the mammalian testis. Developmental Biology $2006299250-256$.

16 Stikkelbroeck NMML, Suliman HM, Otten BJ, Hermus ARMM, Blickman JG \& Jager GJ. Testicular adrenal rest tumours in postpubertal males with congenital adrenal hyperplasia: sonographic and MR features. European Radiology 200313 1597-1603.

17 Mari M, Cagnazzi E, Bollito E \& Bellina M. Ectopic adrenal cortex tissue in the spermatic cord in association with testicular cancer. Urologia Internationalis 200473 191-192.

Received 8 June 2008

Accepted 4 July 2008 